\title{
Why Clinical Nurses Couldn't Adhere to Standard Precautions Adequately Despite their High Adherence Intention? A Quantile Regression Approach
}

\section{Jin Suk Kim}

Hallym University Medical Center Kangnam/Graduate School of Nursing

Eunhee Lee ( $\boldsymbol{\sim}$ ehlee@hallym.ac.kr)

Hallym University https://orcid.org/0000-0002-4729-6692

\section{Research}

Keywords: standard precautions, healthcare-associated infections, surveillance, nurse staffing, hand hygiene

Posted Date: April 5th, 2021

DOI: https://doi.org/10.21203/rs.3.rs-381200/v1

License: (9) This work is licensed under a Creative Commons Attribution 4.0 International License. Read Full License 


\section{Abstract}

Background: Standard precautions (SPs) are the minimum healthcare-associated infection (HAl) prevention practice, which is important for preventing HAls in all healthcare settings. This study aimed to investigate adherence to SPs using a survey and surveillance, and the factors affecting observed adherence to SPs.

Methods: This study included 163 clinical nurses who were directly involved in patient care to examine the adherence to SPs. We compared the adherence according to the investigative methods and represented them by box plots. Quantile regression analysis was used to identify the factors affecting the observed adherence to SPs to determine the factors influencing each adherence quantile.

Results: The observed adherence to SPs was 76.8 out of 100 points, while the self-reported adherence to SPs was approximately 95 points. Among the SP components, the observed adherence to hand hygiene was under 70 points, which was the lowest score. The statistically significant factors were self-reported adherence and work experience in the $25 \%$ quantile, self-reported adherence and working department in the $50 \%$ quantile, and nothing in the $75 \%$ quantile.

Conclusion: Since inadequate adherence to SPs might lead to increase HAls, we should consider both individual and organizational risk factors and construct prevention strategies for adequate adherence to SPs.

\section{Introduction}

The entire world is currently facing a crisis due to the outbreak of the novel coronavirus. The outbreak of infectious diseases has a great impact on society at large, including healthcare and the economy. Especially, as South Korea suffered extensive damage due to the Middle East Respiratory Syndrome (MERS) outbreak in 2015, the importance of infection control has been emphasized in such activities as amendments to infectionrelated laws and regulations [1].

Hospitals are one of the environments most vulnerable to infectious diseases because patients are susceptible to infections not only due to their age and comorbidity, but also surgery or invasive procedures they receive in the hospitals [2, 3]. In fact, healthcare-associated infections (HAls), referring to infections acquired from healthcare delivery in healthcare settings, have a greater impact than other diseases [4]. Therefore, in a situation where the occurrence of new infectious diseases continues to increase, healthcare providers are trying to reduce and prevent HAls. However, despite various prevention efforts, more than one million patients experience HAls annually in the United States and Europe [4, 5]. Since the MERS outbreak in 2015, South Korea has established and applied more proactive policies and strategies to prevent HAls. However, HAls remain a challenge to overcome.

Standard precautions (SPs) are the minimum HAl prevention practice that should be applied proactively in all healthcare settings [6, 7]. The World Health Organization (WHO) also recommends that healthcare providers comply with SPs as a sustainable and widely applicable basic strategy for the prevention of HAls [8]. Most countries have adopted SPs for national health policy infection control. SPs include the eight strategies of 1) hand hygiene, 2) the use of personal protective equipment (PPE), 3) cough etiquette, 4) isolation precaution, 5) environmental infection control including disinfection and sterilization, 6) handle textiles and laundry carefully, 
7) safe infection practices, 8) healthcare worker safety [9]. Adequate adherence to SPs is a major strategy for preventing HAls between patients and healthcare workers and can reduce infection exposure for patients as well as healthcare providers $[7,10]$. Hence, SPs are the simplest and most important way to reduce the risk of microbial transmission in healthcare settings.

Clinical nurses in charge of patient care for 24 hours have the highest risk of becoming infected with pathogens and spreading pathogens to other patients. Therefore, clinical nurses should strictly comply with SPs for protecting themselves and at the same time protecting other patients. Previous studies reported that knowledge and awareness of individual factors significantly influenced the adherence of nurses to SPs [11-13]. In addition, among organizational factors, both the physical environment, including workload and safe environment and the organizational culture were shown to influence the adherence to SPs by clinical nurses [14-16].

However, although many previous studies investigated the factors influencing adherence to SPs, a limitation of many studies was the investigation of only self-reported adherence to SPs rather than observed adherence. In addition, some studies reported that the observed adherence to SPs was extremely low compared to that of self-reports $[17,18]$. Hence, since whether self-reported adherence, which shows intention, is linearly associated with actual adherence has not been determined, we cannot consider self-reported adherence as actual adherence. Therefore, this study aimed to compare the difference between self-reported adherence and observed adherence and investigate the factors affecting observed adherence to SPs compared to real adherence.

\section{Methods}

\section{Study setting and sample}

This study conducted both a survey and surveillance to examine the adherence of clinical nurses to SPs. We surveyed and observed 163 clinical nurses who worked at one general hospital in South Korea. As this study aimed to investigate the adherence to SPs, we only included the nurses directly caring for patients in departments such as general ward and special care unit. Therefore, nurse managers and nurses working in departments not directly related to patient care were excluded from this study.

To compare the adherence to SPs according to the investigative methods, we conducted both a survey and surveillance. To establish validity and inter-observer reliability when conducting the observational study, we assigned the nurses working in infection control departments as observers. These observers received specialized training in surveillance, prevention, and control of HAls. In addition, we developed a structured instrument and trained the observers several times using the developed instrument for obtaining consistent results from each observer. Moreover, to reduce the external effects on the observation study as much as possible, we conducted the observational study and survey at intervals of more than one week. The study received ethical approval from Hallym University Medical Center Kangnam (HKS2018-06-017).

\section{Variables.}


We investigated adherence to SPs through a survey and surveillance using the same instrument developed by referring to the Center for Disease Control (CDC) guidelines [9]. Among the eight SP strategies, the instrument used to measure adherence to SPs in this study included three strategies directly related to patient care, which were hand hygiene, safe injection practice, and the use of PPE during patient care. Each strategy consisted of five items, for a total of 15 items. The survey measured adherence on a 5-point Likert scale and yes or no responses on the observational study. Observed adherence was calculated as the percentage performed out of all 15 items. To compare the differences according to the research methods, the self-reported adherence based on a 5 -point scale was converted to a 100-point scale.

We determined four variables associated with adherence to SPs including knowledge, awareness, safe environment, and patient safety climate derived from several previous studies $[6,13,15]$. Among the four variables, knowledge, awareness, and safe environment were measured in this study by modifying the instrument developed by Jo and Choi [19] according to the CDC guidelines [9]. Knowledge, consisting of 25 items, was measured by yes or no answers, with total score ranging from 1 to 25 . Awareness, consisting of five items, was measured on a 3-point Likert scale (2-highly agree, 1-agee, and 0-disagree), with total scores ranging from 0 to 20. Safe environment consisted of seven items, which were measured by yes or no, with total scores ranging from 0 to 7. Patient safety climate was measured using an instrument developed by Moon [20], which consisted of 10 items scored on a 7-point Likert scale.

\section{Analysis}

The nurse characteristics are reported as the mean and standard deviation (SD) for continuous variables and frequencies and percentages for categorical variables. Descriptive analysis of the two types of adherence, selfreport and observation, and the four influencing variables are reported as the mean and SD. We compared adherence according to the investigative method after making the measurement levels the same. We indicated the distribution of overall adherence and each strategy of SP as box plots. The correlation between the four influencing variables and the two types of adherence was analyzed by Pearson's correlation coefficient.

Quantile regression analysis was used to identify the factors affecting observed adherence to SPs as we assumed that the variables influencing each adherence quantile were different and the observed adherence had a skewed shape and data outliers. We compared the results from quantile regression and standard linear regression. Stata SE version 14.2 was used for all statistical analyses.

\section{Results}

A total of 163 nurses were included in this study. Their characteristics are shown in Table 1. Most (92.6\%) of the nurses were women, and their average age was 27.5 years. Most nurses had a bachelor's degree or a diploma. The average work experience was 54.9 months, and newly graduated nurses who worked less than a year accounted for $23.3 \%$ of the participants in this study. Most nurses had received education in infection control. This study included nurses who worked in various departments, not only general care units such as general ward and integrated nursing unit but also special care units such as the intensive care unit (ICU) and the emergency room (ER). We also investigated the nurses who worked in the integrated care unit. Integrated care units were implemented in 2013 in South Korea to decrease the caregiving burden and improve the quality of care. This unit provides care service with a nursing staff increased to about twice that of a general ward. 
Table 1

Characteristics of clinical nurses $(\mathrm{N}=163)$

\begin{tabular}{|c|c|c|c|}
\hline Characteristics & Categories & $\mathbf{N}(\%)$ & Mean \pm SD \\
\hline \multirow[t]{2}{*}{ Gender } & Men & $12(7.4)$ & \\
\hline & Women & $151(92.6)$ & \\
\hline \multirow[t]{3}{*}{ Age (years) } & $<26$ & $81(49.7)$ & \multirow[t]{3}{*}{$27.45 \pm 5.45$} \\
\hline & $26 \sim 30$ & $51(31.3)$ & \\
\hline & $>30$ & $31(19.0)$ & \\
\hline \multirow[t]{3}{*}{ Education level } & Diploma & $48(29.4)$ & \\
\hline & Bachelor's & $105(64.5)$ & \\
\hline & Master's & $10(6.1)$ & \\
\hline \multirow[t]{4}{*}{ Work experience (months) } & $<12$ & $38(23.3)$ & \multirow[t]{4}{*}{$54.9 \pm 66.7$} \\
\hline & $12 \sim<36$ & $54(33.1)$ & \\
\hline & $36 \sim<60$ & $22(13.5)$ & \\
\hline & $\geq 60$ & $49(30.1)$ & \\
\hline \multirow[t]{4}{*}{ Work department } & ICU & $50(30.9)$ & \\
\hline & Integrated care unit & $13(8.0)$ & \\
\hline & ER & $19(11.7)$ & \\
\hline & General ward & $80(49.4)$ & \\
\hline \multirow[t]{2}{*}{ Education on infection control } & Yes & $155(95.1)$ & \\
\hline & No & $8(4.9)$ & \\
\hline
\end{tabular}

Table 2 shows the level of four variables associated with adherence to SPs and according to the study methods of survey and surveillance. The average knowledge scores were 21.5, 13.4 in awareness, 5.9 in patient safety climate, and 7.9 in safe environment. In the case of adherence to SPs, the self-reported adherence was 4.8, which was approximately 95 points after converting to a 100-point scale. In contrast, the observed adherence to SPs was 76.8 points, which was lower than the self-reported adherence (Fig. 1). Hence, the adherence to SPs varied considerably depending upon the investigation method. The surveillance results were low compared to the survey results, not only in overall scores but also for each strategy. According to each SP strategy, the difference between self-reported and observed adherence was lowest in safe infection practice, which was 90 or higher in both methods. However, hand hygiene and the use of PPE showed a difference of 20 points or more between the self-reported and observed scores. The observed adherence to hand hygiene was under 70 points, which was the lowest of the SPs. 
Table 2

Levels of knowledge, awareness, patient safety climate, safe environment, and adherence to standard precautions

\begin{tabular}{|llll|}
\hline Variables & Items & Mean \pm S.D & [Min - Max] \\
\hline Knowledge & 25 & $21.5 \pm 1.9$ & {$[14.0-25.0]$} \\
\hline Awareness & 5 & $13.4 \pm 1.4$ & {$[8.0-15.0]$} \\
\hline Safe environment & 7 & $7.9 \pm 1.0$ & {$[7.0-12.0]$} \\
\hline Patient safety climate & 10 & $5.9 \pm 0.8$ & {$[2.3-7.0]$} \\
\hline Self-reported adherence & 15 & $4.7 \pm 0.3$ & {$[3.1-5.0]$} \\
\hline Observed adherence & 15 & $76.8 \pm 19.6$ & {$[16.7-100.0]$} \\
\hline
\end{tabular}

Table 3

Correlation between knowledge, awareness, safe environment, patient safety climate, and adherence to standard precautions

\begin{tabular}{|c|c|c|c|c|c|c|}
\hline \multirow[t]{2}{*}{ Variables } & \multicolumn{6}{|c|}{$r(p$-value $)$} \\
\hline & 1 & 2 & 3 & 4 & 5 & 6 \\
\hline 1. Knowledge & 1 & & & & & \\
\hline \multirow[t]{2}{*}{ 2. Awareness } & 0.15 & 1 & & & & \\
\hline & $(0.061)$ & & & & & \\
\hline \multirow[t]{2}{*}{ 3. Safe environment } & -0.15 & -0.36 & 1 & & & \\
\hline & $(0.057)$ & $(<0.001)$ & & & & \\
\hline \multirow[t]{2}{*}{ 4. Patient safety climate } & 0.25 & 0.42 & -0.45 & 1 & & \\
\hline & $(0.002)$ & $(<0.001)$ & $(<0.001)$ & & & \\
\hline \multirow[t]{2}{*}{ 5. Self-reported performance } & 0.10 & 0.32 & -0.41 & 0.57 & 1 & \\
\hline & $(0.227)$ & $(<0.001)$ & $(<0.001)$ & $(<0.001)$ & & \\
\hline \multirow[t]{2}{*}{ 6. Observed performance } & 0.06 & -0.01 & -0.13 & 0.17 & 0.28 & 1 \\
\hline & $(0.450)$ & $(0.889)$ & $(0.091)$ & (0.035) & $(<0.001))$ & \\
\hline
\end{tabular}

Among the four variables related to the adherence to SPs, all variables except knowledge had a significate correlation with self-reported adherence. However, observed adherence had a significant correlation with only patient safety climate $(r=0.17, p<0.35)$. In addition, there was a significant correlation between the results of the two methods $(r=0.28, p<0.001)$.

In the case of observed adherence to SPs, the average score was lower than the self-reported scores, and the distribution was larger than the self-reported scores as well. Observed adherence ranged widely from 16.7$100 \%$, and the distribution of the observed adherence to SPs showed a skewed shape presented in Fig. 2. Therefore, we investigated the factors associated with observed adherence to SPs using quantile regression. To 
prevent multicollinearity, we included work experience instead of age. There was no multicollinearity in the regression model because the variance inflation factor (VIF) was less than the threshold values (1.21-1.90). In the ordinal least square (OLS), the statistically significant variables were self-reported adherence, work experience, and work department. Regarding each quantile, the statistically significant variables were selfreported adherence and work experience in the $25 \%$ quantile, and self-reported adherence and work department in the $50 \%$ quantile. However, there were no significant variables associated with observed adherence in the $75 \%$ quantile (Table 4). In the case of the work department, the number of patients the nurses responsible for was the lowest in the ICU, followed by the integrated care unit, ER, and the general ward. In the regression model, the adherence of nurses in the general ward was significantly lower than that of the ICU nurses. Hence, if nurses take care of many patients, the actual adherence to SPs will inevitably decrease, especially in the middle adherence quantile. 
Table 4

Factors influencing observed compliance with standard precautions using quantile regression

\begin{tabular}{|c|c|c|c|c|c|c|c|c|c|}
\hline \multirow[t]{3}{*}{ Variables } & & \multirow{2}{*}{\multicolumn{2}{|c|}{$\begin{array}{l}\text { OLS } \\
\text { Regression }\end{array}$}} & \multirow{2}{*}{\multicolumn{2}{|c|}{$\begin{array}{l}\text { QR at } \\
0.25 \text { quantile }\end{array}$}} & \multirow{2}{*}{\multicolumn{2}{|c|}{$\begin{array}{l}\text { QR at } \\
0.50 \text { quantile }\end{array}$}} & \multirow{2}{*}{\multicolumn{2}{|c|}{$\begin{array}{l}\text { QR at } \\
0.75 \\
\text { quantile }\end{array}$}} \\
\hline & & & & & & & & & \\
\hline & & Coeff & SE & Coeff & SE & Coeff & SE & Coeff & SE \\
\hline \multirow[t]{7}{*}{$\begin{array}{l}\text { Personal } \\
\text { factors }\end{array}$} & $\begin{array}{l}\text { Self- } \\
\text { reported } \\
\text { adherence }\end{array}$ & $11.91^{\star}$ & 5.36 & $16.23^{*}$ & 8.18 & $13.62^{\star}$ & 6.30 & 13.61 & 7.62 \\
\hline & $\begin{array}{l}\text { Education } \\
\text { on } \\
\text { infection } \\
\text { control }\end{array}$ & 1.06 & 6.60 & -9.92 & 22.38 & -9.83 & 8.11 & -1.15 & 9.46 \\
\hline & $\begin{array}{l}\text { Work } \\
\text { experience } \\
\text { (months) }\end{array}$ & $0.12^{\star \star}$ & 0.03 & 0.16 ** & 0.02 & 0.10 & 0.05 & 0.06 & 0.04 \\
\hline & $\begin{array}{l}\text { Education } \\
\text { level (base: } \\
\text { Diploma) }\end{array}$ & & & & & & & & \\
\hline & Bachelor's & -2.29 & 3.21 & -4.04 & 5.26 & -2.00 & 3.47 & 0.58 & 3.83 \\
\hline & Graduate & -4.53 & 7.86 & -13.89 & 7.03 & -2.03 & 11.65 & -0.70 & 8.79 \\
\hline & $\begin{array}{l}\text { Gender } \\
\text { (Base: } \\
\text { Men) }\end{array}$ & 3.42 & 5.99 & 7.21 & 14.39 & 6.58 & 10.99 & -1.27 & 7.49 \\
\hline \multirow[t]{5}{*}{$\begin{array}{l}\text { Organizational } \\
\text { factors }\end{array}$} & $\begin{array}{l}\text { Patient } \\
\text { safety } \\
\text { climate }\end{array}$ & -0.58 & 2.28 & -0.39 & 4.00 & -0.94 & 2.18 & 1.63 & 3.27 \\
\hline & $\begin{array}{l}\text { Work } \\
\text { department } \\
\text { (base: ICU) }\end{array}$ & & & & & & & & \\
\hline & $\begin{array}{l}\text { Integrated } \\
\text { care unit }\end{array}$ & 2.27 & 5.85 & -1.98 & 8.49 & -2.49 & 5.00 & -1.36 & 9.80 \\
\hline & $\begin{array}{l}\text { Emergency } \\
\text { room }\end{array}$ & 0.17 & 5.18 & 1.39 & 7.68 & -2.22 & 6.31 & 3.36 & 6.01 \\
\hline & $\begin{array}{l}\text { General } \\
\text { ward }\end{array}$ & $-7.52^{\star}$ & 3.68 & -11.03 & 5.81 & $-8.43^{\star}$ & 3.86 & -2.32 & 5.67 \\
\hline \multicolumn{2}{|l|}{ Constant } & 18.34 & 23.23 & -6.94 & 38.34 & 23.37 & 36.88 & 14.78 & 27.74 \\
\hline \multicolumn{2}{|l|}{$\mathrm{R}^{2}$} & .18 & & .15 & & .15 & & .13 & \\
\hline
\end{tabular}


This study investigated adherence to SPs using a survey and surveillance. The self-reported adherence investigated by the survey was 4.7 points out of 5 points, which means that most nurses responded that they always performed ( 5 points on the Likert scale) or often performed (4 points on the Likert scale) all SP items. The results were slightly higher than those of previous studies $[6,13,21,22)$. However, the results from previous studies were also high, reporting around 4 out of 5 points. This might be attributed to the importance of infection control emphasized in overall healthcare settings after the MERS outbreak in South Korea. The excessively high results might also be attributed to the investigation method. As healthcare providers regard that adequate adherence to SPs is a healthcare providers' obligation, self-reported adherence, which measured the intention to adhere to SPs might be higher than the actual adherence. Contrary to the intention, the actual performance, which was the observed adherence to SPs in this study, was low in this study, which appears to be consistent with the findings of other studies $[17,18]$.

Among the SP sub-strategies, although hand hygiene is a basic practice of infection control, the adherence to hand hygiene was the lowest (below 70 points) of all SP strategies. Most previous studies have also reported similar results regarding low compliance with hand hygiene [10,23]. Moreover, in the case of no observers such as in video surveillance, hand hygiene adherence was more worse [24]. Hence, real hand hygiene adherence might be extremely low because results that excluded the observer's effect would be more realistic. Poor hand hygiene was revealed to be a risk factor for HAls $[10,18,25]$. Therefore, an investigation of the barriers hindering the adherence of nurses' hand hygiene and effective strategies to improve adherence is needed. The observed adherence to PPE use was much lower than the self-reported adherence as well and the difference between the two methods was as large as that for hand hygiene. Compared to hand hygiene and safe injection, PPE use is affected more by external factors such as equipment shortages and nurses' workload [26]. Thus, the observed adherence to PPE use in this study might have been affected by working conditions on the surveillance day. Among SP strategies, the adherence to safe infection practices had the highest self-reported and observed scores. Since safe infection practice has the most direct effect on patients, scores should be increased as close to 100 points as possible by implementing various strategies.

As mentioned earlier, healthcare providers recognize the importance of perfect adherence to SPs and have a high intention to do that [14], consistent with the results of this study. Hence, their low performance can never be attributed to low knowledge or low awareness. We should identify other variables or barriers rather than knowledge or awareness. Recently, some studies reported organizational conditions such as overcrowding and emergencies as factors hindering the adherence to SPs by clinical nurses $[26,27]$. This study also showed that the observed adherence was associated with work experience and work department in quantile regression, and patient safety climate in correlation analysis. Regarding work experience, the shorter the experience, the lower the adherence to SPs in this study. This finding corroborated that in a study by Murray, Sundin, and Cope (2018), which reported a theory-practice gap of SPs in newly graduated nurses [28]. This gap has been attributed to the difficulties newly graduated nurses have in managing the pressure of limited time compared to experienced nurses working under the same conditions $[28,29]$. When nurses with inadequate competency have to take care of many patients, they cannot adequately comply with SPs. Therefore, to improve adherence to SPs, nurse managers should set adequate workloads considering both each nurse's competency and the work conditions. The work department was also an influencing factor in observed adherence to SPs in this study. In this study, we included nurses who worked in special units such as the ICU and ER and general units such as the integrated care unit and general wards. Nurses in the general ward showed the lowest adherence to 
SPs, which was significantly lower than that of the ICU nurses. Nurses in integrated care units in South Korea have more than twice the number of patients to care for as the nurses in general wards [30]. Nurses in integrated care units are in charge of eight patients, whereas nurses in general wards are in charge of more than 15 patients $[30,31]$. Hence, the primary organizational condition, called nurse staffing, influences an individual nurse's performance. This result appears to be consistent with the findings of other investigations, showing that patients in understaffed units were more likely to develop HAls [32-34]. HAls is a nursingsensitive outcome [34]. If structure indicators such as adequate nurse staffing levels are not met, process indicators such as adherence to SPs will inevitably not be met at adequate levels [35]. Consequentially, understaffing conditions and insufficient provision of nursing service lead to increases in HAls. Therefore, setting an adequate level of nurse staffing should take precedence for ensuring adequate adherence to SPs.

In this study, we used quantile regression to investigate the factors associated with adherence to SPs. Through quantile regression, we identified the influencing factors that differed according to the performance level. In the $25 \%$ quantile, work experience was a significant factor, which means that clinical nurses need to be prepared to perform clinical practice. Several studies also have supported the need to enhance work readiness during the early stages of a nurse's career under increased complexity of care and acutely ill patients [36]. In the 50\% quantile, the work department, which referred to how many patients a nurse should be in charge of, was a significant factor. Compared to the ICU, only the general ward showed statistically low adherence to SPS, while other departments such as the emergency room and integrated care unit did not show a significant difference. Some studies have reported that integrated care units in South Korea had a positive effect on patient-centered outcomes such as falls and pressure ulcers $[37,38]$. In the integrated care unit, not only falls and pressure ulcers but also nurses' adherence to SPs could be better than those in the general ward. Moreover, as better adherence to SPs would ultimately improve final outcomes, an integrated nursing care system should show positive effects on reducing HAls. There were no significant factors affecting adherence to SPs in the $75 \%$ quartile because we could not include all variables related to SP adherence and most nurses showed very high adherence to the SPs.

\section{Conclusion}

A great difference in adherence to SPs was found between the survey and surveillance methods. The observed adherence was lower than the self-reported adherence. However, observed adherence was significantly correlated with self-reported adherence. The factors influencing adherence to SPs were organizational factors such as understaffing and work experience rather than knowledge and awareness in the $25 \%$ and $50 \%$ quantile groups. Setting adequate nurse staffing levels and developing strategies to improve competencies for newly graduated nurses are needed to improve adherence to SPs by clinical nurses.

\section{Abbreviations}

SPs: Standard Precautions, HAI: Healthcare-Associated Infection, MERS: Middle East Respiratory Syndrome, WHO: World Health Organization, PPE: Personal Protective Equipment, CDC: Center for Disease Control, ICU: Intensive Care Unit, OLS: Ordinal Least Square, QR: Quantile

\section{Declarations}




\section{Acknowledgments:}

This work was supported by Hallym University.

\section{Author Contributions:}

JS and EH contributed to the study aim, research design and overall structure of the manuscript. EH conducted all the statistical analyses and drafted the manuscript. All authors have read and agreed to the published version of the manuscript.

\section{Funding:}

This research was funded by Hallym University (grant number HRF-202005-009).

\section{Availability of data and materials:}

The data sets used and analyzed during this study can be provided from the corresponding author on reasonable request.

\section{Ethics approval and consent to participate:}

The study was approved by the Institutional Review Board of Hallym University Medical Center Kangnam (HKS2018-06-017). Informed consent was obtained from all nurses involved in the study.

\section{Consent for publication:}

Not applicable.

\section{Competing interests:}

The authors report no conflicts of interest.

\section{References}

1. Lee KM, Jung K. Factors influencing the response to infectious diseases: focusing on the case of SARS and MERS in South Korea. Int J Environ Res Public Health. 2019;16(8).

2. Weber DJ, Anderson D, Rutala WA. The role of the surface environment in healthcare-associated infections. Curr Opin Infect Dis. 2013;26(4):338-44.

3. Facciola A, Pellicano GF, Visalli G, Paolucci IA, Venanzi Rullo E, Ceccarelli M, D'Aleo F, Di Pietro A, Squeri R, Nunnari G, La Fauci V. The role of the hospital environment in the healthcare-associated infections: a 
general review of the literature. Eur Rev Med Pharmacol Sci. 2019;23(3):1266-1278.

4. Smith KM, Machalaba CC, Seifman R, Feferholtz Y, Karesh WB. Infectious disease and economics: The case for considering multi-sectoral impacts. One Health. 2019;7:100080.

5. Cassini A, Plachouras D, Eckmanns T, Abu Sin M, Blank HP, Ducomble T, Haller S, Harder T, Klingeberg A, Sixtensson M, Velasco E, Weiss B, Kramarz P, Monnet DL, Kretzschmar ME, Suetens C. Burden of six healthcare-associated infections on European population health: estimating incidence-based disabilityadjusted life years through a population prevalence-based modelling study. PLoS Med. 2016;13(10):e1002150.

6. Beyamo A, Dodicho T, Facha W. Compliance with standard precaution practices and associated factors among health care workers in Dawuro Zone, South West Ethiopia, cross sectional study. BMC Health Serv Res. 2019;19(1):381.

7. Moralejo D, El Dib R, Prata RA, Barretti P, Correa I. Improving adherence to standard precautions for the control of health care-associated infections. Cochrane Database Syst Rev. 2018;2:CD010768.

8. World Health Organization. Available onlne:

https://www.who.int/csr/resources/publications/standardprecautions/en/ (assessed on 22 February 2021).

9. Centers for Disease Control and Prevention. Standard precautions for all patienbt care. Available at: https://www.cdc.gov/infectioncontrol/basics/standard-precautions.html. Assessed on 22 February 2021.

10. Ojanpera H, Kanste Ol, Syrjala H. Hand-hygiene compliance by hospital staff and incidence of health-careassociated infections, Finland. Bull World Health Organ. 2020;98(7):475-483.

11. Asmr Y, Beza L, Engida H, Bekelcho T, Tsegaye N, Aschale Y. Assessment of knowledge and practices of standard precaution against blood borne pathogens among doctors and nurses at adult emergency room in Addis Ababa, Ethiopia. Emerg Med Int. 2019:2926415.

12. Ndu AC, Arinze-Onyia SU. Standard precaution knowledge and adherence: do doctors differ from medical laboratory scientists? Malawi Med J. 2017;29(4):294-300.

13. Angaw DA, Gezie LD, Dachew BA. Standard precaution practice and associated factors among health professionals working in Addis Ababa government hospitals, Ethiopia: a cross-sectional study using multilevel analysis. BMJ Open. 2019;9(10):e030784.

14. Colet PC, Cruz JP, Alotaibi KA, Colet MKA, Islam SMS. Compliance with standard precautions among baccalaureate nursing students in a Saudi university: A self-report study. J Infect Public Health. 2017;10(4):421-30.

15. Hessels AJ, Larson EL. Relationship between patient safety climate and standard precaution adherence: a systematic review of the literature. J Hosp Infect. 2016;92(4): 349362.

16. Lim JH, Ahn JW, Son YJ. Association between Hospital Nurses' Perception of Patient Safety Management and Standard Precaution Adherence: A Cross-Sectional Study. Int J Environ Res Public Health. 2019;16(23).

17. Lee A, Chalfine A, Daikos GL, Garilli S, Jovanovic B, Lemmen S, Martinez JA, Masuet Aumatell C, McEwen J, Pittet D, Rubinovitch B, Sax H, Harbarth S, Team MS. Hand hygiene practices and adherence determinants in surgical wards across Europe and Israel: a multicenter observational study. Am J Infect Control. 2011;39(6):517-20.

Page $12 / 15$ 
18. Pessoa-Silva CL, Hugonnet S, Pfister R, Touveneau S, Dharan S, Posfay-Barbe K, Pittet D. Reduction of health care associated infection risk in neonates by successful hand hygiene promotion. Pediatrics. 2007;120(2):e382-90.

19. Jo G, Choi JS. Knowledge of and dompliance with standard precautions by nurses in intensive care unit. J Korean Acad Fundam Nurs. 2010;17(1):73-81.

20. Moon JA. Structural model of performance of helathcare-associated infection control guideline in hospital nurses. Doctoral thesis, Chonnam National University, Gwangju February 2015.

21. Cirelli MA, de Figueiredo RM, Zem-Mascarenhas SH. Adherence to standard precaution in the peripheral vascular access. Rev Lat Am Enfermagem. 2007;15(3):512-4.

22. Alkaff FF, Salamah S, Syamlan AT, Sukmajaya WP, Nugraha RA, Jonatan M, Sulistiawati S. Standard precaution adherence among clinical medical students in HIV and non-HIV ward in Indonesia. J Educ Health Promot. 2020;9:122.

23. Wiemken TL, Hainaut L, Bodenschatz H, Varghese R. Hand hygiene compliance surveillance with time series anomaly detection. Am J Infect Control. 2019;47(12):1449-52.

24. Sharma S, Khandelwal V, Mishra G. Video surveillance of hand hygiene: a better tool for monitoring and ensuring hand hygiene adherence. Indian J Crit Care Med. 2019;23(5): 224-6.

25. Chiu NC, Chi H, Tai YL, Peng CC, Tseng CY, Chen CC, Tan BF, Lin CY. Impact of wearing masks, hand hygiene, and social distancing on influenza, enterovirus, and all-cause pneumonia during the coronavirus pandemic: retrospective national epidemiological surveillance study. J Med Internet Res. 2020;22(8):e21257.

26. Houghton C, Meskell P, Delaney H, Smalle M, Glenton C, Booth A, Chan XHS, Devane D, Biesty LM. Barriers and facilitators to healthcare workers' adherence with infection prevention and control (IPC) guidelines for respiratory infectious diseases: a rapid qualitative evidence synthesis. Cochrane Database Syst Rev. 2020;4:CD013582.

27. Donati D, Biagioli V, Cianfrocca C, Marano T, Tartaglini D, De Marinis MG. Experiences of compliance with standard precautions during emergencies: A qualitative study of nurses working in intensive care units. Appl Nurs Res. 2019;49:35-40.

28. Murray M, Sundin D, Cope V. New graduate registered nurses' knowledge of patient safety and practice: a literature review. J Clin Nurs. 2018;27(1-2):31-47.

29. Ghaffari M, Rakhshanderou S, Safari-Moradabadi A, Barkati H. Exploring determinants of hand hygiene among hospital nurses: a qualitative study. BMC Nurs. 2020;19(1):109.

30. Kim J, Kim S, Park E, Jeong S, Lee E. Policy issues and new direction for comprehensive nursing service in the National Health Insurance. J Korean Acad Nurs Adm. 2017;22(3):312-22.

31. Cho S, Lee JY, June KJ, Hong KJ, Kim Y. Nurse staffing levels and proportion of hospitals and clinics meeting the legal standard for nurse staffing for 1996 2013. J Korean Acad Nurs Adm. 2016;22(3):209-19.

32. Mitchell BG, Gardner A, Stone PW, Hall L, Pogorzelska-Maziarz M. Hospital staffing and health careassociated infections: a systematic review of the literature. Jt Comm J Qual Patient Saf. 2018;44(10):61322.

33. Shang J, Needleman J, Liu J, Larson E, Stone PW. Nurse staffing and healthcare-associated infection, unitlevel analysis. J Nurs Adm. 2019;49(5):260-5.

Page 13/15 
34. Twigg DE, Kutzer Y, Jacob E, Seaman K. A quantitative systematic review of the association between nurse skill mix and nursing-sensitive patient outcomes in the acute care setting. J Adv Nurs. 2019;75(12):340423.

35. Breyer JZ, Giacomazzi J, Kuhmmer R, Lima KM, Hammes LS, Ribeiro RA, Kops NL, Falavigna M, Wendland EM. Hospital quality indicators: a systematic review. Int J Health Care Qual Assur. 2019;32(2):474-87.

36. Baumann A, Crea-Arsenio M, Hunsberger M, Fleming-Carroll B, Keatings M. Work readiness, transition, and integration: The challenge of specialty practice. J Adv Nurs. 2019;75(4):823-33.

37. Kim J, Kim S, Park J, Lee E. Multilevel factors influencing falls of patients in hospital: The impact of nurse staffing. J Nurs Manag. 2019;27(5):1011-9.

38. Kim J, Lee JY, Lee E. Risk factors for newly acquired pressure ulcer and the impact of nurse staffing on pressure ulcer incidence. J Nurs Manag. (in press).

\section{Figures}

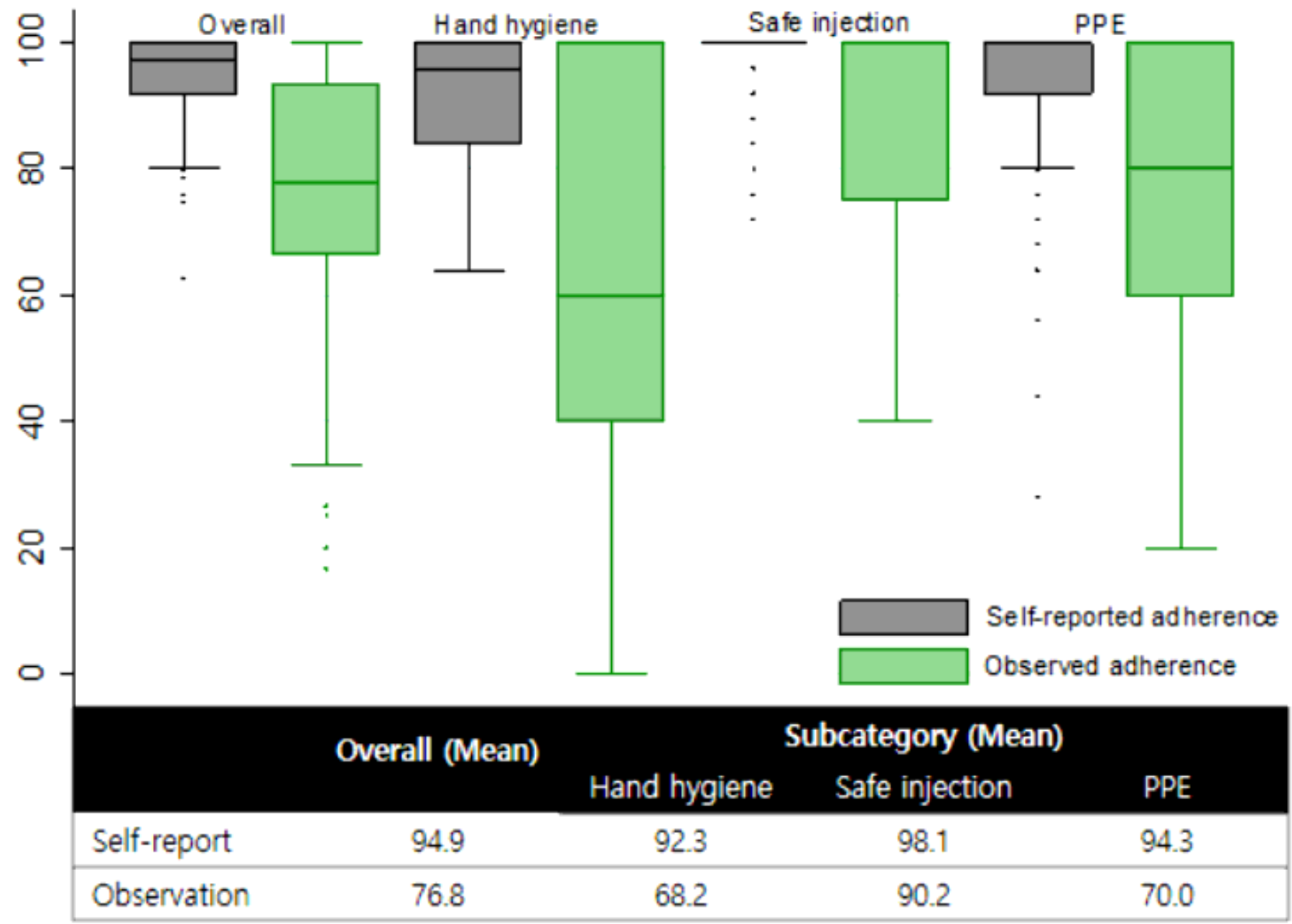

Figure 1

Comparison between self-reported adherence to SPs and observed adherence to SPs. 


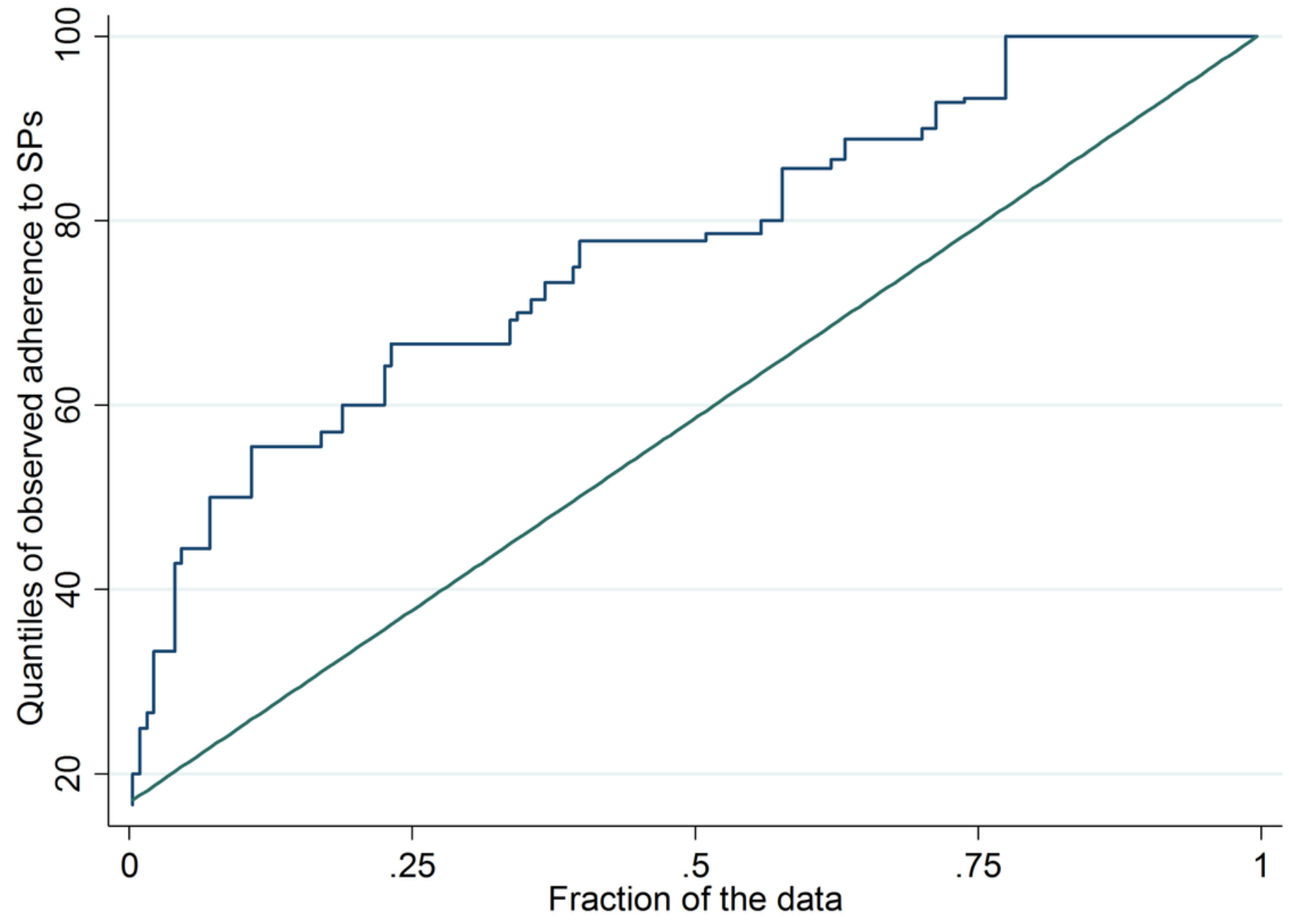

Figure 2

Distribution of observed adherence to standard precautions 